\title{
Open business models: A case study of system-on-a-chip (SoC) design foundry in the integrated circuit (IC) industry
}

\author{
Po-Young Chu and Wan-Chen Chen* \\ Department of Management Science, National Chiao Tung University, Hsinchu, R.O.C. Taiwan, \\ Accepted 23 June, 2011
}

\begin{abstract}
In the global IC industry, business models have evolved into design foundry models and manufacturing foundry service models over the past twenty years. The concept of system-on-a-chip (SoC) refers to integrating all components of a computer or other electronic system in a single integrated circuit (IC). Due to the increasing complexities of SoC devices, it is impossible for one IC design house to have the state-of-the-art expertise required to make all the hardware and software components required for an SoC. Based on SoC needs for intellectual property (IP) reuse and design reuse, this study analyzes a new open business model, called design foundry. Design houses must use a design foundry, an innovation intermediary, to combine their internally generated IPs with IPs acquired externally. This paper uses the SoC design foundry as a case to examine the evolution, SoC problems, and the core value of innovation intermediaries in the whole IC industry. Further, it demonstrates how design foundries create ecological benefits by teaming up with suppliers and customers in the IC industry. This research is the first known study to explore the emerging service gaps, value creation, and value capture processes created by an SoC design foundry.
\end{abstract}

Key words: Open business models, open innovation, design foundry, innovation intermediary, system-on-a-chip (SoC), integrated circuit (IC) Industry.

\section{INTRODUCTION}

Embracing the trend of globalization, changes in make-or-break rules are accelerating in the global market. The concept of innovation is also undergoing revolutionary modifications. Enterprises that concentrate on their own strengths to create innovations are finding it much more difficult to be successful, and the division of innovative activities has become the key to an enterprise's future success. Adopting an open business model is therefore a critical strategy for developing win-win opportunities.

Previous research have emphasized on the development strategy (Chang and Hsu, 1998; Chu et al., 2005), collaboration strategy (Ku et al., 2007), the valuation of

\footnotetext{
*Corresponding author. E-mail: woanjenchen.tw@gmail.com, woanjenchen.ms94g@nctu.edu.tw
}

intangible assets (Chu et al., 2008) and firm's capability on performance (Sher and Yang, 2003) for an IC company. However, there have been few studies available concerning the IC firm's business model and emerging service gaps of the IC industry. This paper is to fill this gap by analyzing a new open business model, called system-on-a-chip (SoC) design foundry. Especially, this study also examines the processes of value creation and value capture that created by an $\mathrm{SoC}$ design foundry.

Open business models integrate value chain activities into various products or services. Open business models have emerged as the new key to survival, transcending geographical boundaries, accelerating the speed of product life cycles, and resolving the lack of resources. Firms that adopt the classical closed business model are responsible for the product concept, product design, product manufacturing, product marketing, and post-sale services. However, firms with open business models only 
participate in the highest degree of competitiveness and earn the maximum company's profit. Joint efforts are also made to work with active partners to complete the product or service. Through the division of work and integration at the global level, consumers will be able to gain the maximum benefits, while the most competitive firms in each section of the value chain also benefit from the dramatic increase in their economies of scale and increased profit.

Many successful multinational corporations have adopted open innovation and open business models, including IBM, P and G, Apple, Intel, and a number of companies that have been frequently mentioned in relevant literatures (Chesbrough, 2006; Dodgson et al., 2006). For example, in the context of the semiconductor research and development ( $R$ and $D)$, IBM has revised the prior unilateral participation model by inviting Sony, $\mathrm{AMD}$, and several other companies to jointly raise more than one billion US dollars for capital. IBM also recruited hundreds of specialty research personnel to develop the next-generation IC chip. This development not only averted a tremendous increase in IBM's research budget, but also achieved better-than-expected collaborative results.

A design foundry is a new business model in the IC industry. The design foundry business model not only provides the services of IP authorization and IC design, but also offers turnkey solutions. Following Moore's Law, the pace of semiconductor development is so fast that most IC design companies can hardly catch up. Therefore, reusable IC design, reusable IP configurability, and programmability have evolved into an important trend in the IC industry. As an innovation intermediary, a design foundry integrates various IPs from different companies, including itself, to create ecological benefits by teaming up with suppliers and buyers in the IC industry.

In open business models, key supplier and customers become business partners, entering into relationships in which both risks and rewards are shared. A design foundry is able to enhance the competitiveness of all of the firms in it cluster against larger competitors, who do everything their own. This study introduces successful open innovation experiences and a case study of SoC design foundry in the IC industry.

\section{LITERATURE REVIEW}

The concept of "Open Innovation" is defined as an enterprise breaking through its traditional organizational boundaries by extracting innovative ideas, knowledge, and resources from the external environment and sharing unused internal knowledge and innovations with the outside world. This new division of labor drives the organizational model of innovation. To tap into this new division of labor, companies must adopt an open business model. However, in searching and drafting contracts among collaborative partners, many companies encounter the problems of uncertainty and transaction frequency. Generally, this refers to the problems of transaction costs. For these reasons, this section briefly reviews the literature on transaction costs, classic closed innovation models, open business models, and innovation intermediaries.

\section{Transaction costs and intermediaries}

The concept of "Transaction Costs" was originally presented in the article "The Nature of Manufacturers" written by Coase (1937). Williamson (1975) further elaborated on the concept by dividing product costs into production costs and transaction costs. The sources of transaction costs include information search costs, contract costs, supervision costs, contract enforcement costs, etc (Casson, 1982; Dyer and Singh, 1998). Consider the example of information search costs. While current international trade barriers have been gradually reduced, it is still difficult for manufacturers to search and select potential trade partners. Therefore, scholars believe that cross-border trading often has the characteristics of information asymmetry. As a result, since the intermediary has a better understanding of both the buying and selling part of the business, the transaction costs of trading will be lower if a business is traded through an intermediary. Therefore, both buyers and sellers conduct business through an intermediary to reduce the transaction costs for both parties (Anderson and Coughlan, 1987; Klein et al., 1990; Spulber, 1996).

Spulber (1996) defined the intermediary as an agent. The work of an agent is to buy products from suppliers, and sell those products to customers or clients to complete the transaction between the buyer and the seller. To put it simply, the tasks of an intermediary are mainly to (1) seek buyers, and increase their desire to purchase; (2) assist suppliers and buyers in creating a balance price negotiation; (3) ensure the smooth execution of transactions, including payments, product delivery, inventory, etc. A typical intermediary functions like a stock or insurance trader, seeking potential buyers and sellers in the market, and negotiating deals for both parties. The market for intermediaries is called "secondary innovation markets." Ashish Arora, the marketing executive of Logitech Company, referred to the secondary innovation market as a market in which new products are invented but not yet sold. In secondary innovation markets, sellers develop creativity and techniques, which buyers transform into products and services that are brought to market for customers.

In terms of the relationship between the intermediary, the supplier, and the buyer, scholars believe that the intermediary plays the role of a broker for buyers and sellers (Casson, 1998; Hennart and Kryda, 1998). The key to maintaining this intermediary relationship is to 
control the information held by the buyers and the sellers. The existence of an intermediary is due to the inability of the buyer or the seller to efficiently collect the necessary information. At the same time, such abilities cannot be sold via market mechanisms (Casson, 1998). The task of collecting information is accomplished by the intermediary. Therefore, if the intermediary can understand the existence of information asymmetry, and then provide appropriate guarantees by transmitting related information regarding the quality of products, they would be able to strike a deal by raising the confidence of both buyers and sellers (Tellis and Wernerfelt, 1987; Kirmani and Rao, 2000; Skaggs and Snow, 2004).

\section{Classic close innovation}

Economist Joseph Alois Schumpeter first proposed the concept of innovation in 1912. Schumpeter regarded innovation as: (1) introduction of a new product; (2) adoption of a new production method; (3) development of a new market; (4) acquisition of a new supply source for raw materials or semi-finished products; or (5) implementation of a new corporate organization format. Innovation causes new-market disruptions by creating new product or services or recombining production elements. Generally speaking, innovation is associated with corporate management secrets and operational uniqueness, and that technical innovation and $R$ and $D$ should therefore be conducted by the corporation internally. However, recent studies indicate that if an organization can collaborate with external partners in joint innovations or systemic innovations, more optimal innovation effects can be achieved (Chesbrough and Teece, 2002; Chesbrough, 2003; Duysters et al., 1999; Teece, 1996).

Innovative firms must be capable of understanding external knowledge and how various technologies differ from internal corporate knowledge. Firms must also have the foresight to apply this external knowledge and technologies (Amin and Cohendet, 2004). Firms can utilize various methods to proceed with the research and development collaborations, including technology licensing, joint ventures, or strategic alliances (Contractor and Lorange, 2004). The foundation of $R$ and $D$ collaboration among firms can also change over time and due to variations in corporate activities (Hagedoorn, 2002). Because of increasing technological development costs and shortened product life cycles in severely competitive markets, companies must concentrate on their core competencies and work with other corporate organizations in the industry.

\section{Open business models and innovation intermediaries}

Open innovation is the application of external knowledge or technology by a firm in the innovation process (Chesbrough, 2003). Chesbrough pointed out that open corporations must be able to utilize external technology or knowledge in the same way that they would utilize internal knowledge. Firms can acquire more advanced knowledge or technology through this mechanism. From their external strategic partners, corporations can identify customer needs and create more competitive products. The utilization of external strengths for facilitating innovations or transferring intra-firm research to other firms to conduct innovation activities is known as "Open Innovation." Open innovation is different from the classical innovation model. While the creation of all technological innovations is conducted by the firm in a classical innovation model, open innovation does not require developing products or services from the beginning to the end. On the contrary, existing accomplishments from outside of the firm are utilized, enabling the acceleration of technology and product developments. This is how open innovation differs from closed innovation (Chesbrough, 2003).

In comprehensive management models, the successful implementation of open innovation depends on collaboration. As an extension of open innovation, open business models underscore a concept of industry ecosystem. Excluding the external $R$ and $D$ viewpoint of open innovation, open business models emphasize the interorganizational activities. Open business models are a new type of innovative work division model that encompass value creation and value extraction. First, open business models define the development of new products or services from raw materials to the final consumer. These activities create net value. Second, open business models capture value by establishing a unique resource, asset, or position within that series of activities that allows the firm to enjoy a competitive advantage (Chesbrough, 2006; Vanhaverbeke and Cloodt, 2006).

If firms can cooperate with external partners in joint innovations or systemic innovations, they can achieve superior innovation results (Chesbrough and Teece, 2002; Maula et al., 2006; Teece, 1996). Through external strategic partners, firms will better understand customer needs, and create much more competitive products. Open business models are a framework for transforming innovations and technologies into economic accomplishments, and help firms learn how to transform technological ability into economic value.

Secondary innovation markets and innovation intermediaries have arisen to manage the outside-in dimension and inside-out dimensions of open innovation (Chesbrough, 2006). As business models become more open, there will be more opportunities to introduce external ideas and technology into business models. However, whenever a company acquires an external technology, its legal status must be known. For this reason, intermediate markets for technology profoundly change the management of IP in the world of open 
innovation. A secondary innovation market refers to a market emerging after the creation of a new technology, but before that technology has been sold. In this intermediary market, ideas and technologies are developed by sellers and sold to buyers, who take these ideas and technologies and sell them to consumers. Innovation intermediaries function as brokers or market makers, and try to bring parties together to complete a transaction. They help companies of many different sizes participate in the emerging secondary markets for innovation and IP, and craft more open business models. Their chief capability is their ability to create, own, market, and sell IP to other firms.

\section{RESEARCH QUESTIONS AND METHOD}

This research is based on a case study. The case study research method can be adopted in exploratory, narrative or explanatory research (Yin, 2008). Our research questions of "what" and "how," are suitable for case study research. In the global IC industry, business models have evolved into design foundry models and manufacturing foundry service models over the past twenty years. The concept of SoC refers to integrating all components of a computer or other electronic system in a single IC. Due to the increasing complexities of SoC devices, it is impossible for one IC design house to have the state-of-the-art expertise required to make all the hardware and software components required for an SoC. Based on SoC needs for IP reuse and IC design reuse, this study aims to answer questions that include:

1. What are the SoC problems for an IC industry company when it develops an IC chip, especially those of a smaller IC company? 2. How a design foundry solve the SoC problems for all other IC companies and how it create the ecological benefits for whole IC industry.

To address these questions, we develop a case study that analyses the evolution of the IC industrial infrastructure and the SoC problems in the IC industry. In particular, we explain the value creation and value capture processes created by an SoC design foundry from an ecological perspective. Our approach was to deconstruct the basic framework and the challenges of the IC industry. We then explains how a design foundry plays a key role in forming new industrial partnerships in the IC industry and creating ecological benefits through open business models.

\section{Historical background of the IC Industry}

Different companies in the same industry frequently adopt different strategies and exactly opposite business models. Integrated device manufacturing (IDM) and fabless strategies are both prevalent in the IC industry, and both can be well justified. Due to changes in the industrial environment, companies select different strategies depending on their comparative strengths. The reasons for adopting different strategies and business models, such as vertical integration or outsourcing, are highly dependent on the size of the market, converging technical standards, and a sufficient number of vendors.

In the development of the semiconductor industry, three stages followed immediately after the invention of multiple integrated circuits. These transformations all resulted from different ways of solving the problems of IC design. The revolution of the IC industry can be traced back to the 1970s. In the first stage, IDM companies emerged and dominated other competitors. At that time, IDM provides a comprehensive set of services in the IC industrial value chain. IDM companies such as Intel, Motorola, National Semiconductor, and Philips offer services to their customers from the very start to the end, including designing and manufacturing their own IC products. An IDM company adopts a vertically integrated business model, and must allocate resources not only to $R$ and $D$, but also to building increasingly expensive manufacturing and fabrication facilities (Figure 1).

In contrast, 'fabless' or IC design houses focus solely on designing and selling products. After the IC industrial changes in the 1980 s, each company began to focus on individual niche markets. IDM started to outsource some activities to other IC companies. These firms outsourced manufacturing to foundry service companies, such as Taiwan Semiconductor Manufacturing Company (TSMC) in Taiwan. The establishment of wafer foundries completely revolutionized traditional IDM business models, allowing fabless companies to reduce their costs and focus their attention on IC design. Wafer foundries, IC assembly companies and IC test com- panies could concentrate their attention on their core competencies. Big IC design houses engaged in IC design and IC marketing. Similar to IDM, big IC design houses also opened their IPs to certain types of processes. In other words, IPs from big IC design houses were, in a sense, more convenient than those from IDM. At that time, small fabless companies gained the ability to compete with large-scale IDM companies. As a result, the entire industry has shifted from a manufacturing-centric market to a more customer-oriented market.

Intellectual property (IP), at the same time, has become crucial to the IC industry. The more functions and effects a semiconductor can get, the more complex its design will be. Therefore a new business model, IP vendors, was created in the 1990s. These examples included MIPS and ARM. IP vendors in this stage simply provide pure IP and IP libraries, and make money from patents and patent-related fees.

Based on SoC's needs for IP reuse and design reuse, a new business model emerged in the 2000s. A typical case is a design foundry, which is capable of providing IP and IC design services to customers. Design foundries integrate the technologies of IC manufacturing from wafer foundries, IC assembly companies and IC test companies for small IC design houses, which do not have the ability to seek their assistance for mass production of an IC chip.

Open business models provide an effective solution to the problems of decreasing product life cycle and increasing $R$ and $D$ expenses. As an extension of open innovation, open business models integrate value chain activities into various products or services. Once a company adopts an open business model and cooperates with external organizations, the transaction costs are realized. The costs are incurred in trading goods or services. High transaction costs are often the cause of the problems. Furthermore, a company is difficult to survive when it faces higher transaction costs Therefore, the company requires an intermediary for the buyer and the seller to collect the necessary information efficiently, thereby reducing the transaction costs.

Through global division and cooperation, design foundries have played the important roles of inter-mediator and integrator, generating more value and mutual interest between foundries and IC design companies. To explain the dynamic phenomenon of the IC industry, this study focuses on the difficulties that IC companies faced. This paper also explains why IC companies require an intermediary when they confront high transaction costs.

\section{The common service gap and SoC problems for every part of the IC industry}

The IPs of an SoC chip are usually developed by different companies. When designing a new IC, companies can experience 


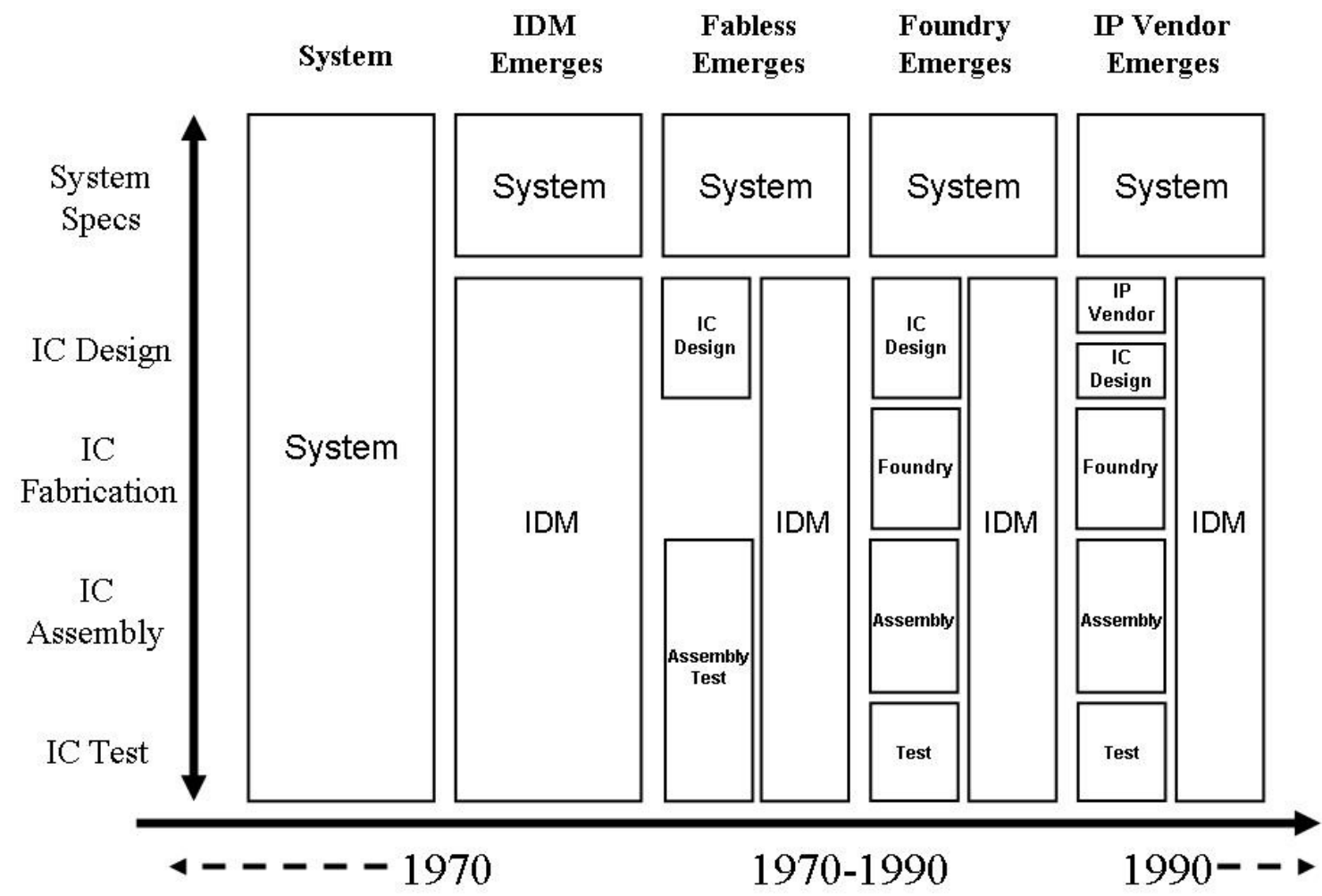

Figure 1. Evolution of the IC industrial infrastructure (source: Industrial technology information services of the Ministry of Economic affairs (MOEA, 1997).

even more complicated and numerous problems due to transaction costs such as insufficient intellectual property rights (IPR), and a lack mutual trust and cooperation in outsourcing. Getting all IP providers' heads together and working out IPR questions is one of the first things that an $\mathrm{SoC}$ design foundry must do. From the business perspective of the evolution of the IC industry, there are several predicaments in integrating authorized IP coordinator for majority of IC companies. IC companies can encounter several key issues including the following:

1. IP vendors: Because they lack an innovation intermediary that provides the infrastructure for IP networking, IP vendor companies cannot service small IC design houses. Due to service complexity, IP vendors incur high operation costs when they license IP to other companies. Because some IP vendors cannot service all middle- or small-scale IC design houses, they need a service agency or innovation intermediary to provide their own IPs to those licensees. 2. Wafer foundries, IC assembly companies and IC test companies: Due to limited resources, wafer foundries cannot pay attention to small IC design houses. The difficulties that both parties experience are the result of a poor communication bridge. There are same problems among IC assembly companies, IC test companies and small IC design houses. Wafer foundries, IC assembly companies and IC test companies must always integrate diverse processes with a lower budget. While designing their IC layouts, middle- or small-scale IC design houses sometimes do not take IC manufacturing innovations into consideration. Wafer foundries usually do not have sufficient resources to "teach" small IC design houses the process of combining various IPs. Thus, wafer foundries often need a service agent to effectively communicate with small IC design houses. In the same vein, IC assembly companies and IC test companies also need the support of an innovation intermediary.
TSMC, following the $80 / 20$ rule, focuses on big clients with a high manufacture yield, and devotes fewer resources to servicing thousands of small IC design houses. The problem of poor communication between wafer foundries and small IC design houses could be solved if small IC design houses would work with a service agent and use the $\mathrm{SoC}$ model to eliminate tedious revision and design rules.

3. IC design houses: IC design houses experience two major problems. The first one is that small IC design houses often cannot acquire licensed IP without the help of IP vendors and wafer foundries. The other problem is that their customers might change into potential competitors after acquiring the necessary IPs. Due to the fact that no company can own all major IPs and other IP specifications at the same time, it is important that IC design houses choose suitable IPs and electronic design automation (EDA) tools. In this case, super IC design houses might work. Alternately, it may be possible to make a deal with IP vendors or wafer foundries, but middle- or small-scale IC design houses can never get support from these two. Furthermore, as soon as IC design houses start to authorize and sell their IP products, their clients often become potential competitors. This is also a problem that many IC design houses have encountered. Other problems of IC design houses, such as time-consuming design programs, complex design patterns, and higher costs, still need to be solved. To solve these problems, IC design houses need a mediator to integrate useful IPs from a larger IP pool.

\section{STUDY RESULT AND FINDING}

Currently, companies in the IC industry are becoming 


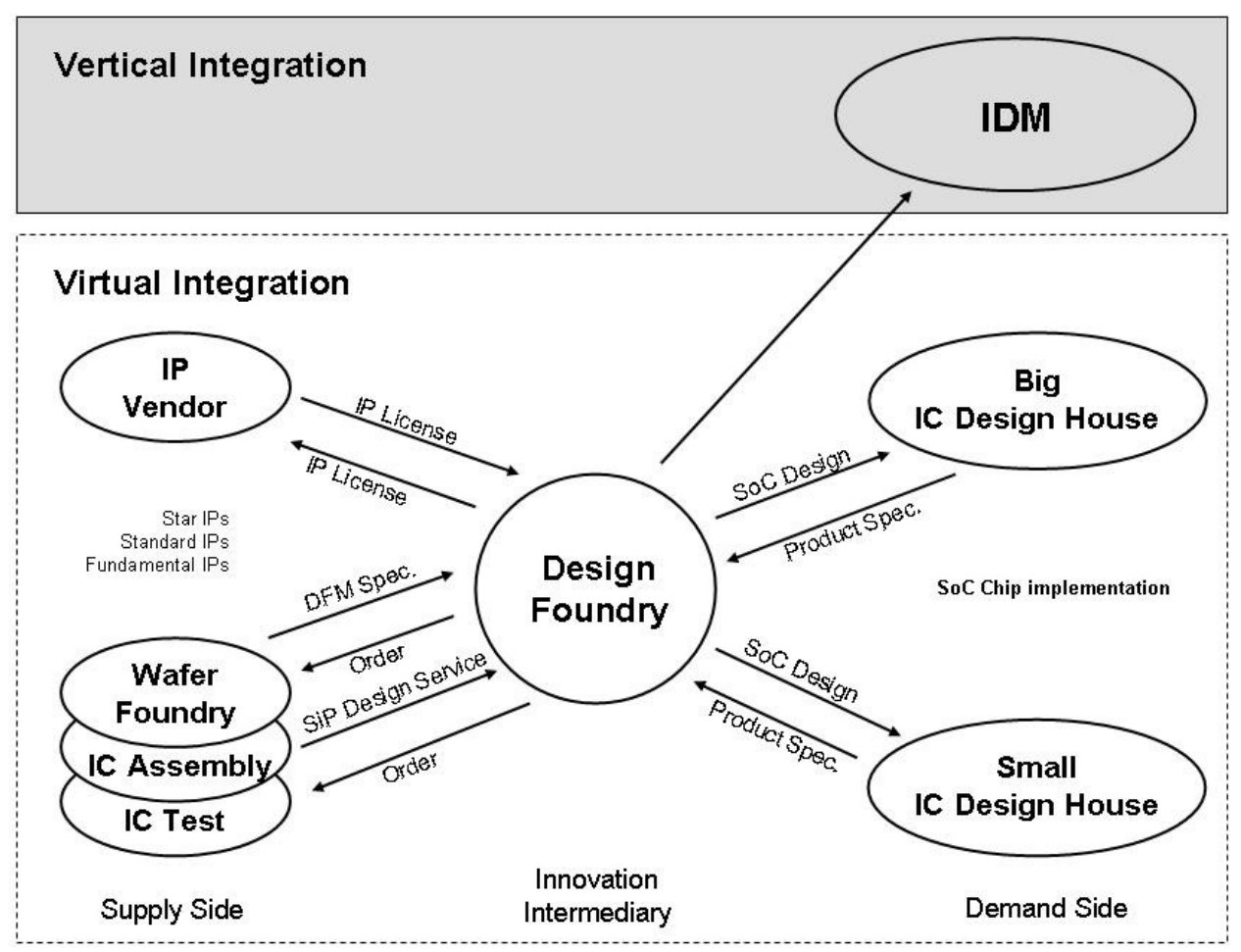

Figure 2. The switching ecology of design foundry

more and more open. To open up their business models, firms in the IC industry should tap into intermediate markets for ideas and innovations. The IC industry review discussed earlier outlines some problems of an IC company in the IC industry. These difficulties also include the rising costs of technology development and the emerging trend of decreasing product life cycles. These difficulties make $R$ and $D$ investment under the closed model of innovation increasingly non-sustainable.

\section{The ecological benefit of the IC industry}

Design foundries accelerate the process of production, provide suppliers with customer information, and meet their needs. This innovation intermediary allows all organizations to enjoy various ecological benefits. Open innovation takes advantage of the new division of innovation labor. This division also appears in inter- mediate markets for innovation. Within this international division and cooperation, the design foundry has played the important roles of inter-mediator and integrator.

\section{Open business models: Design foundries play a key role as an innovation intermediary}

Design foundries not only provide the services of IP authorization and IC design, but also offer turnkey solutions, namely a complete package from the very beginning of the design stage to the very end. Design foundries were established in response to the growing trend towards IP and design reuse in SoC devices. Compared with traditional IC design houses, design foundries do not do their own brands' development and IC marketing. They do whatever their customers want, and only cater to their specific needs. Design foundries make money by charging their customers design fees, which thus enjoying relatively lower competition than other IP-related business. Wafer foundries are to IDM what design foundries are to IC design houses. In short, a design foundry is a bridge between foundries and customers, creating new value and generating collaboration interest.

Through design foundries, the whole IC industry can form an integral IC industry ecosystem enjoying the two functions of the open business model, value creation and value capture. This approach would solve many service gaps and problems. Each organization could earn profit and derive benefit from the resulting integral IC industry ecosystem (Figure 2).

\section{The core value of design foundries}

There are value creation and value distribution that is created by a design foundry. It can create a total solution for SoC design services to their customers. Through cost 
sharing on most advanced IP and wafer manufacturing among IC design houses, a design foundry also can improve new product time to market rates. To reduce risks of IP theft and piracy, design foundries can integrate IPs through several different IC firms. IC firms can also reduce their $R$ and $D$ investment costs and achieve a faster time to market by cooperating with design foundries. Different companies in the value chain of the IC industry have their own specialties and unique IPs. If these IPs could be used repeatedly and legally by solving issues such as IP licensing and pirating, then good IC designs could be widely circulated and made more profitable. As a result, many design foundries are formed to provide IP related services such as IP searching, designing, integration, and authentication.

Before the recent developments in the industry, IC design houses could not deliver a product to their clients without the help of a wafer foundry. Furthermore, not all IC design houses could directly collaborate with wafer foundries. At that time, design foundries could help both IC design houses and wafer foundries solve the problem of poor cooperation.

At the beginning of the designing process, if IC design houses could receive assistance and sufficient information form design foundries, they would not only be able to reduce the time and cost to produce a design, but could also reduce manufacturing risks. The information provided by design foundries includes which wafer foundries have which certified IPs (including silicon verification and production proven), what manufacturing processes are suitable for a particular IP, and where the appropriate design tools can be acquired.

If wafer foundries can understand the needs of IC design houses, they could reduce production difficulties and effectively manage products manufactured or certified by IC design houses. This allows wafer foundries to effectively manage their production, control their delivery time, and expand their customer services, improving overall wafer foundry performance.

\section{Design foundries how to collaborate and share utility with other IC companies}

Figure 2 shows what good benefits that an IC company enjoys when it cooperate with a design foundry.

\section{IP vendors}

An IP vendors' primary business is to authorize usage rights of developed IP to others. Through the coordination and integration of IP by design foundries, IP vendors would be able to occupy a favorable market position, enhance authorization opportunities for IP, and coordinate with other IP vendors to introduce packaged IP, thus generating more profit. More specific benefits include xthe following:

i. The nurturing of star IP vendors: Providing a favorable environment to small IP vendors can nurture these IP vendors into star IP vendors.

ii. Reuse IP: The reusable IP can help IP vendors reduce costs and shorten product cycle time. Further, an IP vendor can receive royalties from various companies only through one design foundry.

iii. Industry standard: Creating the industry standard of product IP.

\section{Wafer foundries}

For wafer foundries, the process of integrating the IP market via design foundries, enhances business opportunities and attracts more potential customers. With design foundries taking care of the problems of authorization and royalty payments for the customers, professional wafer foundries can not only improve the utilization of the manufacturing resources, but also actively provide standard IP blocks for customers. The advantages that design foundries afford to wafer foundries include the following:

i. Design for manufacturing (DFM): If IC design engineers followed DFM guidelines of wafer foundries, they can locate and solve the problems of potential production yield in the initial design process. For instance, TSMC provides its customers with IC design rules in designing the IC layout.

ii. Focused on silicon-proven IP and start-up: Wafer foundries can attract more customers and create more opportunities to cultivate customers by using foundry-specific and silicon-proven IP.

iii. Reduce switching costs and enhance communication efficiency: With the help of design foundries, wafer foundries can decrease the frequency of communication with customers.

\section{IC assembly companies and IC test companies}

With the help of the design foundries, IC assembly companies and IC test companies can bring more customers by providing system-in-a-package (SiP) service. SiP is multiple integrated circuits (ICs) enclosed in a single package or module. SiP service is to complete the system integration in a single package. It provides verification (testing) services, overall manufacturing process support, and documentation and application support for their customers. From product design to mass production, design foundries integrate the technologies of IC assembly and IC test with SiP service to provide higher performance SoCs and shortening time-to-market that make IC design houses' products more competitive. 
Table 1. Revenue growth rate and CAGR of IC companies.

\begin{tabular}{llcccccc}
\hline \multirow{2}{*}{ IC companies } & \multicolumn{5}{c}{ Revenue growth rate (\%) } & Compound annual growth rate \\
\cline { 3 - 7 } & & \multicolumn{5}{c}{$\begin{array}{c}\text { Year } \\
\text { (CAGR) }\end{array}$} \\
\cline { 3 - 7 } & & $\mathbf{2 0 0 4 - 2 0 0 5}$ & $\mathbf{2 0 0 5 - 2 0 0 6}$ & $\mathbf{2 0 0 6 - 2 0 0 7}$ & $\mathbf{2 0 0 7 - 2 0 0 8}$ & $\mathbf{2 0 0 8 - 2 0 0 9}$ & 2004-2009 (\%) \\
\hline Design foundry & Company A & 58.14 & 111.08 & 108.08 & 32.81 & -10.91 & 52.39 \\
IP vendor & Company B & 53.71 & 15.50 & 6.35 & 6.20 & -10.38 & 12.44 \\
Wafer foundry & Company C & 7.58 & 18.59 & 0.72 & 7.93 & -15.17 & 3.30 \\
IC assembly/test & Company D & 11.69 & 19.50 & 0.74 & -6.65 & -9.17 & 2.66 \\
IC design house & Company E & 16.25 & 32.66 & 17.87 & 25.60 & -6.52 & 16.37 \\
IDM & Company F & 13.50 & -8.87 & 8.34 & -1.95 & -6.54 & 0.53 \\
\hline
\end{tabular}

There benefits about cost effective develop by design foundries also help IC assembly companies and IC test companies reduce the problems of communication with customers and create more opportunities to gather customers.

\section{IC design houses}

After design foundries develop and integrate the IP market, IC design houses can use basic IP modules to make multiple products with diverse designs. To shorten the time of IC design, IC design houses inevitably use others' IP components when designing a new IC chip. After acquiring IP licensing from IP vendors, large IC design houses can directly deal with IP vendors and wafer foundries. However, smaller IC design houses were not able to directly cooperate with IP vendors and wafer foundries. Therefore, when design foundries integrate majority of IPs and simplify the process of IP authorization, small IC design houses can obtain IP licensing agreements and reduce their R\&D costs. For IC design houses, further advantages of cooperating with design foundries include the following:

i. Providing useful IP source: Simplifying the process of authorization and obtaining IP license.

ii. Time to market: Accelerating new product time to market by understanding advanced IP process.

iii. Total solution: Creating a total solution for SoC design services that includes design foundries, wafer foundries, and IP vendors.

In summary, the business models of IC companies need to open up and incorporate the benefit of intermediate markets for innovation and IP, while managing the risks associated with those markets. Consider the example of some IC companies. Table 1 shows that the revenue growth rate and compound annual growth rate (CAGR) for IC companies in the past five years since 2004. Through a design foundry, Companies $A$ to $E$ formed an industrial partnership in the IC industry. Company $F$ is an IDM company. We replaced Companies $A$ to $F$ with company names, because of non-disclosure information. Company A has increased at a CAGR of $52.39 \%$ over a five-year period, representing impressive growth in the IC industry for the period 2004 to 2009. Company B and Company E grew at a $12.44 \%$ and a $16.37 \%$ CAGR, respectively, while Company $\mathrm{C}$ and Company $\mathrm{D}$ had lower CAGR in the same period. The lowest CAGR of $0.53 \%$ was shown by Company $\mathrm{F}$. These figures indicate that IP-enabled business and fabless companies have grown faster than IC manufacturers during the observed period (2004 to 2009). IDM companies grew even more at a lower CAGR than did IC manufacturers. This data confirms that the more business models open up, the more benefits IC companies can create and capture. With the support of design foundries, IC design houses can compete with IDM companies. With IP reuse and IP integration from IP vendors and design foundries, the design cycle of an IC chip can be reduced. This, in turn, increases the speed at which IC companies can achieve CAGR. Compared with IDM, firms in the IC industry can create a win-win situation by adopting open business models.

\section{DISCUSSION AND CONCLUSION}

If a company adopts an open business model, it can create its business model as a platform to lead its industry, including both suppliers and customers. Open business model highlight the inter-organizational activities. In this industry ecosystem, an innovative intermediary must have not only sufficient industry knowledge to integrate value chain activities into various products or services, but must also have specialized abilities to solve problems efficiently among collaborative partners. In the IC industry, design foundries play a key role as innovation intermediary, creating a platform for effectively organizing and coordinating the work of many others. Through a platform like design foundry, each organization can earn profit and derive benefit from the ecosystem of the IC industry.

The SoC design foundry is an exemplar case of an open business model in practice. In conclusion, the IC industry has adopted many of the features of an open innovation model, including how design foundries form a 
bridge between buyers and suppliers in the IC industry, providing a great benefit to the entire IC industry.

Open innovation increases the breadth of business and technological interdependencies in partnerships. Open business models contain various compound theories and numerous innovation processes. Examining the roles of innovation may assist the development and testing of open innovation theory. An important continuing research question is the extent to which industries justify the roles of innovation intermediary, what their interdependent characteristics are, how innovations can be applied, and how innovation intermediaries enable open business models to be managed economically.

\section{REFERENCES}

Amin A, Cohendet $P$ (2004). Architectures of Knowledge: Firms, Capabilities, and Communication. Oxford: Oxford University Press.

Anderson E, Coughlan AT (1987). International Market Entry and Expansion via Independent or Integrated Channels of Distribution. J. Market., 51(1): 71-82.

Casson M (1982). The Entrepreneur: An Economic Theory. Cheltenham: Edward Elgar Publishing.

Casson M (1998). The Economic Analysis of Multinational Trading Companies in G. Jones (ed.). The Multinational Traders (London: Routledge), pp. 22-47.

Chang PL, Hsu CW (1998). The Development Strategies for Taiwan's Semiconductor Industry. IEEE Trans. Eng. Manage., 45(4): 349-356.

Chesbrough HW, Teece DJ (2002). Organizing for Innovation: When is Virtual Virtuous? Harv. Bus. Rev., 80(8): 127-134.

Chesbrough HW (2003). The Era of Open Innovation. MIT Sloan Manage. Rev., 44(3): 35-41.

Chesbrough HW (2003). Open Innovation: The New Imperative for Creating and Profiting from Technology. Boston: Harvard Business School Press.

Chesbrough HW (2006). Open Business Models: How to Thrive in the New Innovation Landscape. Boston: Harvard Business School Press.

Chesbrough HW (2007). Why Companies Should Have Open Business Models. MIT Sloan Manage. Rev., 48(2): 22-28.

Chu PY, Hsiung HH, Huang CH, Yang CY (2008). Determinants of the Valuation of Intangible Assets- A Contrast between Taiwanese and American IC Design Houses. Int. J. Technol. Manage., 41(3/4): 336-358.

Chu PY, Teng MJ, Huang CH, Lin HS (2005). Virtual Integration and Profitability: Some Evidence from Taiwan's IC industry. Int. J. Technol. Manage., 29(1/2): 152-172.

Coase RH (1937). The Nature of the Firm. Economica, 4(16): 386-405.

Contractor FJ, Lorange P (2004). Why Should Firms Collaborate? The Strategic and Contractor, P. Lorange (eds.). Cooperative Strategies and Alliances in International Business: Joint Ventures and Technology Partnership between Firms (Oxford: Elsevier Science Ltd), pp. 3-30.
Dodgson M, Gann D, Salter A (2006). The Role of Technology in the Shift towards Open Innovation: The Case of Procter \& Gamble. $R$ D Manage., 36(3): 333-346.

Duysters G, Kok G, Vaandrager M (1999). Crafting Successful Strategic Technology Partnerships. R D Manage., 29(4): 343-351.

Dyer JH, Singh H (1998). The Relational View: Cooperative Strategy and Sources of Interorganizational Competitive Advantage. Acad. Manage. Rev., 23(4): 660-679.

Hagedoorn J (2002). Inter-firm R\&D Partnerships: An Overview of Major Trends and Patterns since 1960. Res. Policy., 31(4): 477-492.

Hennart JF, Kryda GM (1998). Why Do Traders Invest in Manufacturing? in G. Jones (ed.). The Multinational Traders (London: Routledge), pp. 213-227.

Kirmani A, Rao AR (2000). No Pain, No Gain: A Critical Review of the Literature on Signaling Unobservable Product Quality. J. Market., 64(2): 66-79.

Klein S, Frazier GF, Roth VJ (1990). A Transaction Cost Analysis Model of Channel International Markets. J. Market. Res., 27(2): 196-208.

Ku KC, Gurumurthy CK, Kao HP (2007). Inter-firms Collaboration of Joint Venture in IC Foundry Business. Technovation., 27(5): 296-305.

Maula MVJ, Keil T, Salmenkaita JP (2006). Open Innovation in Systemic Innovation Context in H.W. Chesbrough, W. Vanhaverbeke, J. West (eds.), Open Innovation: Researching a New Paradigm (Oxford: Oxford University Press), pp. 241-257.

Sher PJ, Yang PY (2003). The Effects of Innovative Capabilities and R\&D Clustering on Firm Performance: The Evidence of Taiwan's Semiconductor Industry. Technovation, 25(1): 33-43.

Skaggs BC, Snow CC (2004). The Strategic Signaling of Capabilities by Service Firms in Different Information Asymmetry Environments. Strateg. Organ., 2(3): 271-291.

Spulber DF (1996). Market Microstructure and Intermediation. J. Econ. Perspect., 10(3): 135-152.

Teece DJ (1996). Firm Organization, Industrial Structure, and Technological Innovation. J. Econ. Behav. Organ., 31(2): 193-224.

Tellis GJ, Wernerfelt B (1987). Competitive Price and Quality under Asymmetric Information. Market. Sci., 6(3): 240-253.

Vanhaverbeke W, Cloodt M (2006). Open Innovation in Value Networks in H.W. Chesbrough, W. Vanhaverbeke, J. West (eds.). Open Innovation: Researching a New Paradigm (Oxford: Oxford University Press), pp. 258-287.

Williamson OE (1975). Markets and Hierarchies: Analysis and Antitrust Implications. New York: Free Press.

Yin RK (2008). Case Study Research: Design and Methods. London: Sage. 